\title{
The Diagnostic Utility of Anti-Mutated Citrullinated Vimentin Antibodies, Anti-Cyclic Citrullinated Peptide Antibodies and Rheumatoid Factor in Rheumatoid Arthritis
}

\author{
Amina Badr Eldin ${ }^{1}$, Sameh A. Mobasher ${ }^{1}$, Gehan Hegazy ${ }^{2}$ \\ Departments of Internal Medicine ${ }^{1}$, Ain Shams University; \\ Medical Biochemistry ${ }^{2}$, National Research Center; Egypt
}

\begin{abstract}
Objectives: This study aims to investigate the diagnostic sensitivity and specificity of anti-mutated citrullinated vimentin (anti-MCV) antibodies for rheumatoid arthritis (RA) in comparison to IgM rheumatoid factor (RF) and Anti-Cyclic Citrullinated Peptide Antibodies (anti-CCP) and to assess their clinical significance particularly as a marker of RA activity. Patients and Methods: 60 patients with different rheumatic diseases 40 patients with RA and 20 patients with other rheumatic diseases (disease controls) were recruited from Ain Shams University Hospitals, and 20 persons (healthy controls) All participants underwent history taking, clinical examination, laboratory and radiological investigations, and calculation of disease activity score DAS-28 for each RA patient. Enzyme-linked immunosorbent assay (ELISA) techniques were used to detect RF-IgM, anti-CCP antibodies, and anti-MCV antibodies. Results: The sensitivity of anti-MCV antibodies was $95 \%$ with $97.1 \%$ specificity. For anti-CCP antibodies the sensitivity was $95 \%$ and the specificity was $100 \%$. The sensitivity of RF was $72.5 \%$ with $97.1 \%$ specificity. Anti-CCP antibodies have higher diagnostic specificity and positive predictive value than $\mathrm{RF}$ and anti-MCV antibodies. The best cut-off value for the anti-MCV test was found at $22.7 \mathrm{U} / \mathrm{L}$, while that for Anti-CCP antibodies and RF were $20 \mathrm{ul}$ and $44 \mathrm{IU} / \mathrm{ml}$ respectively. Of RA patients with positive RF, $86.2 \%$ were anti-MCV antibodies positive, including only $6.8 \%$ with negative Anti-CCP. Of patients with negative RF, $81.8 \%$ were positive for anti-MCV, including 9\% who tested negative for anti-CCP. Conclusion: Our results suggest that anti-MCV antibodies may be valuable for diagnosing RA and that, it may be better to assay both anti-MCV and anti-CCP in RF -negative RA patients without replacing them. Long-term study is required to find out whether anti-MCV antibodies can be used as predictive test for incidence of RA. [Egypt J Rheumatology \& Clinical Immunology, 2014; 2(1): 19-25]
\end{abstract}

Key Words: rheumatoid arthritis, anti-MCV, IgM RF, Anti-CCP antibodies.

\section{INTRODUCTION}

Rheumatoid arthritis (RA) is a chronic systemic inflammatory autoimmune disease characterized by chronic joint inflammation that often leads to destruction of bone and cartilage. ${ }^{1}$ Early treatment improves the outcome and therefore early diagnosis is crucial. Although the etiology of RA remains unknown, it is widely accepted that multiple accumulative/ compounding genetic and environmental 'hits' are required between the initiation of self-peptide recognition, subsequent loss of tolerance, and the development of autoimmunity. ${ }^{2}$ So, auto antibodies are of special interest in diagnosing the disease. Rheumatoid factors (RFs) were the first biological markers discovered

Correspondence to Amina Badr Eldin, Departments of Internal Medicine, Ain Shams University; Egypt

e-mail: pr.dr.amina@gmail.com for RA and remained for many years the only laboratory criterion included in the old American College of Rheumatology criteria for RA classification. Two major disadvantages of RF are low specificity and possible absence in the first year of the disease. ${ }^{3}$

Recently, antibodies against citrullinated peptides have gained special importance in the diagnosis of RA. ${ }^{4,5}$ Citrullination (deimination) is a post translational protein modification characterized by the conversion of positively charged arginine amino acid residues into neutrally charged citrulline. The citrullination of arginine to citrulline possibly results in protein unfolding and consequent aberrant recognition by the immune system. Citrullinated antigens are thought to play a pivotal rolein the pathogenesis of RA as they are expressed in inflamed joints and anti-citrullinated protein antibodies are present before clinical disease and are highly specific for RA. ${ }^{6}$ These antibodies are thought to be triggered by the genes that increase susceptibility to RA as well 
as by many environmental agents. ${ }^{4}$ Moreover, antiCCP has been shown to be a specific prognostic marker for RA and predict the erosive or non-erosive progression of the disease. Thus, it is a useful tool for the optimal therapeutic management of RA patients. ${ }^{7}$

Antibodies to other citrullinated peptides or proteins have been suggested as good candidates for diagnosing RA. Vimentin is an intermediate filament that is widely expressed by mesenchymal cells and macrophages and easy to detect in the synovium. Modification of the protein occurs in macrophages undergoing apoptosis, and antibodies to citrullinated vimentin may emerge if the apoptotic material is inadequately cleared. ${ }^{8}$ The first antibodies to citrullinated vimentin described in the literature were anti-Sa antibodies detected by Western blot, which were as specific as anti-CCP but not sufficiently sensitive (20\% to $45 \%)$ to serve as diagnostic tools. ${ }^{9}$ Recombinant mutated citrullinated vimentin (MCV) was produced, ${ }^{10}$ and anti-mutated citrullinated vimentin (anti-MCV) antibodies have been recently recommended to be better diagnostic marker for early arthritis. ${ }^{11}$

The aims of this study were to investigate the diagnostic sensitivity and specificity of anti-mutated citrullinated vimentin (anti-MCV) antibodies for RA in comparison to IgM RF and anti-CCP and to assess their clinical significance particularly as a marker of RA activity.

\section{PATIENTS AND METHODS}

A total of 60 patients with different rheumatic diseases were enrolled in this study: 40 RA patients [they are furthered classified according to the disease duration into 20 patients with early RA $(<1$ year duration) and 20 patients with established disease ( $>2$ years duration)], and 20 patients with other rheumatic diseases as disease controls; (8 with systemic lupus erythematosus (SLE), 5 with spondylo-arthritis (SpA) and 7 patients with Psoriatic arthritis). In addition to 20 volunteers as healthy controls.

All RA patients fulfilled the traditional American College of Rheumatology ACR criteria ${ }^{12}$ ,and the new rheumatoid arthritis diagnostic criteria recently released by $\mathrm{ACR} /$ European league against Rheumatism-EULAR panel. ${ }^{13}$ Patients were either attending the outpatients' clinic or they were inpatients in the Rheumatology Department, Ain Shams University Hospital, between January 2010 and July 2011. Patients were diagnosed and treated in the absence of any information on their serologic status regarding antibody reactivity against citrullinated proteins/peptides.
All patients gave informed consent to participate in the study, which was approved by the Ain Shams Medical ethics committee. Patients underwent; clinical assessment of disease activity by full history taking general and local examinations, Rheumatoid arthritis (RA) disease activity was evaluated using The DAS28 score. A DAS28 score greater than 5.1 imply active disease, less than 3.2 well controlled disease, and less than 2.6 remissions. ${ }^{14}$

Five milliliters of venous blood was withdrawn from each patient and each control, $2 \mathrm{ml}$ was put in a test tube with EDTA anticoagulant for complete blood count (CBC) on (Coulter STKS hematology flow cytometer, Block Scientific, Inc., Bohemia, New York, USA). Erythrocytes sedimentation rate (ESR) was measured by Westergreen method and expressed in $\mathrm{mm} / \mathrm{h}{ }^{15}$ The other $3 \mathrm{ml}$ was put in a clean plain test tube; after centrifugation, the separated serum was stored at $-20{ }^{\circ} \mathrm{C}$ until use. The CRP levels were measured by the turbidimetric method using a photometer (Biosystems S.A., Barcelona, Spain), and a level of $<6 \mathrm{mg} / \mathrm{dl}$ was accepted as normal.

ELISA techniques were used to detectRF (IBL IMMUNO-BIOLOGICAL, GmbH, Hamburg, Germany), anti-CCP antibodies (EUROIMMUNE, Medizinische Labordiagnostika, AG, Lubeck, Germany), and anti-MCV antibodies (ORGENTEC, Diagnostika GmbH, Mainz, Germany). The cut-off values of RF, anti-CCP antibodies, and anti-MCV antibodies were $60 \mathrm{IU} / \mathrm{ml}, 25 \mathrm{IU} / \mathrm{ml}$, and $20 \mathrm{IU} / \mathrm{ml}$, respectively. All those values were recommended by the manufacturers.

\section{Statistical Methods}

IBM SPSS statistics (V. 20.0, IBM Corp., USA, 2011) was used for data analysis. Date was expressed as mean \pm SD (minimum - maximum) or number (percentage) as appropriate. Comparison between different groups was performed using Wilcoxon Rank Sum test and Chi-Square test for parametric and nonparametric data. Correlation was done using Person correlation test. The probability of error at 0.05 was considered significance. Sensitivity, specificity, positive predictive value (PPV), and negative predictive value (NPV), efficacy of IgM-RF, anti-CCP, and anti-MCV were calculated as predictors of RA. The diagnostic sensitivity: It is the percentage of diseased cases truly diagnosed (TP) among total diseased cases $\backslash[\mathrm{TP}+\mathrm{FN}$ (false negative)]. The diagnostic specificity: It is the percentage of non-diseased truly excluded by the test (TN) among total non-diseased cases $\backslash(\mathrm{TN}+\mathrm{FP}$ (false positive)]. PPV: It is the percentage of cases truly diagnosed among total positive cases. NPV: It is the percentage of cases truly negative among total negative 
cases. The efficacy or the diagnostic accuracy of the test: It is the percentage of cases truly diseased plus truly non-diseased among total cases. The ROC was constructed to obtain the most sensitive and specific cutoff for each technique.

\section{RESULTS}

Table (1) shows the demographic information and some laboratory data of RA patients and control groups.

As shown in Table (2), out of 40 patients with RA, 29 patients were positive for RF $(72.5 \%), 35$ patients were positive for anti-CCP antibodies $(87.5 \%)$, and 34 patients were positive for anti-MCV antibodies (85\%). By contrast, of 20patients with other rheumatologic diseases 3 patients were positive for RF $(15 \%)$, none was positive for anti-CCP antibodies $(0 \%)$, and 2 patients were positive for anti-MCV antibodies $(10 \%)$.On the other hand out of 20healthy controls, one person was positive for RF (5\%),none was positive for anti-CCP antibodies ( $0 \%)$, and 2 persons were positive for anti-MCV antibodies (10\%).

Further comparison of the early and established cases of RA shows no significant difference regarding serum levels of RF-IgM (265-25 \pm 213.62 versus 178.75 $\pm 159.96, \mathrm{P}<0.157)$, Anti-CCP $(233.50 \pm 142.91$ versus $273.75 \pm 191.99, \mathrm{P}<0.457)$ and anti-MCV
$(238.89 \pm 167.77$ versus $259.92 \pm 183.84, \quad \mathrm{P}<0.708)$; meanwhile, DAS28 level was significantly higher in early versus established cases of the disease $(4.65 \pm 0.93$ versus $3.37 \pm 1.30)(\mathrm{P}<0.001)$ (Table 3$)$.

Significant positive correlations were found between serum levels of RF-IgM, anti-CCP, anti$\mathrm{MCV}$, and DAS28in early and established rheumatoid arthritis (Table 4).

On distributing the rheumatoid arthritis patients according to the presence of anti-MCV, anti-CCP, and IgM-RF of 40 patients with RA, 29 patients were positive for RF, and 11 patients had negative RF. Of 29 RA patients with positive RF, 25 (86.2\%) were anti-MCV antibodies positive, including only 2 patients $(6.8 \%)$ with negative Anti-CCP. Of 11 patients with negative RF, 9 patients $(81.8 \%)$ were positive for anti-MCV, including 1 patient $(9 \%)$ who tested negative for anti-CCP (Table 5).

Anti-CCP antibodies showed the highest specificity $(100 \%)$ when compared to RF $(97.1 \%)$ and anti-MCV antibodies $(97.1 \%)$, with positive predictive value of $(100 \%)$. Both of anti-MCV antibodies and Anti-CCP antibodies showed the same sensitivity (95\%) when compared to RF $(72.5 \%)$. The best cut-off value for the anti-MCV test was found at $22.7 \mathrm{U} / \mathrm{ml}$, while that for anti-CCP antibodies and RF were 20 $\mathrm{U} / \mathrm{ml}$ and $44 \mathrm{IU} / \mathrm{ml}$ respectively (Table 6).

Table 1. Demographic characteristics and some laboratory data of rheumatoid arthritis (RA) patients and control groups.

\begin{tabular}{|c|c|c|c|}
\hline Variables & $\begin{array}{c}\text { RA patients } \\
(n=40)\end{array}$ & $\begin{array}{c}\text { Disease control } \\
(\mathbf{n}=\mathbf{2 0})\end{array}$ & $\begin{array}{c}\text { Healthy control } \\
(\mathbf{n = 2 0})\end{array}$ \\
\hline Age (years) & $\begin{array}{c}35.73 \pm 12.09 \\
(12.00-58.00) \\
P>0.05\end{array}$ & $\begin{array}{c}31.69 \pm 11.89 \\
(18.00-56.00) \\
\mathrm{P}>0.05 \\
* \mathrm{P}>0.05\end{array}$ & $\begin{array}{c}34.53 \pm 13.85 \\
(17.00-65.00)\end{array}$ \\
\hline $\begin{array}{l}\text { Gender } \\
\text { Male } \\
\text { Female }\end{array}$ & $\begin{array}{c}8(20.00 \%) \\
32(80.00 \%) \\
P>0.05\end{array}$ & $\begin{array}{c}5(25.00 \%) \\
15(75.00 \%) \\
\mathrm{P}>0.05 \\
* \mathrm{P}>0.05\end{array}$ & $\begin{array}{c}4(20.00 \%) \\
16(80.00 \%)\end{array}$ \\
\hline Disease duration (months) & $\begin{array}{l}31.50 \pm 31.13 \\
(1.00-120.00)\end{array}$ & $\begin{array}{c}23.46 \pm 18.59 \\
(2.00-60.00) \\
* \mathrm{P}>0.05\end{array}$ & - \\
\hline $\operatorname{ESR}(\mathrm{mm} / \mathrm{h})$ & $\begin{array}{c}56.78 \pm 17.53 \\
(25.00-105.00) \\
\mathrm{P}<0.0001\end{array}$ & $\begin{array}{c}51.31 \pm 17.33 \\
(27.00-80.00) \\
\mathrm{P}<0.05 \\
* \mathrm{P}<0.05\end{array}$ & $\begin{array}{c}7.13 \pm 2.45 \\
(3.00-12.00)\end{array}$ \\
\hline CRP (mg/dl) & $\begin{array}{c}36.86 \pm 19.53 \\
(16.00-69.00) \\
P<0.0001\end{array}$ & $\begin{array}{c}16.00 \pm 2.77 \\
(13.00-20.00) \\
\mathrm{P}>0.05 \\
* \mathrm{P}<0.05\end{array}$ & $\begin{array}{c}1.58 \pm 0.49 \\
(1.00-2.50)\end{array}$ \\
\hline
\end{tabular}

ESR Erythrocytic sedimentation rate, $\boldsymbol{C R P}$ C-reactive protein, Data are expressed as mean \pm SD (minimum-maximum) or number $(\%) ; \boldsymbol{P}$ Significance versus healthy controls; $* \boldsymbol{P}$ Significance versus disease controls. 
Table 2. Percentage of rheumatoid arthritis (RA) patients and control groups according to the presence of RF-IgM, anti-CCP, and anti-MCV.

\begin{tabular}{lccccc}
\hline \multicolumn{1}{c}{ Variables } & $\begin{array}{c}\text { Early<12m } \\
(\mathbf{n = 2 0})\end{array}$ & $\begin{array}{c}\text { RA patients } \\
(\mathbf{n = 4 0 )} \\
\text { Established }>\mathbf{2 y} \\
(\mathbf{n = 2 0})\end{array}$ & $\begin{array}{c}\text { Total } \\
(\mathbf{n = 4 0})\end{array}$ & $\begin{array}{c}\text { Disease control } \\
(\mathbf{n = 2 0})\end{array}$ & $\begin{array}{c}\text { Healthy controls } \\
(\mathbf{n = 2 0})\end{array}$ \\
\hline RF-IgM $(>60 \mathrm{IU} / \mathrm{ml})$ & $13(65.0 \%)$ & $16(80.0 \%)$ & $29(72.50 \%)$ & $3(15.0 \%)$ & $1(5.0 \%)$ \\
Anti-CCP $(>25 \mathrm{IU} / \mathrm{ml})$ & $17(85.0 \%)$ & $18(90.0 \%)$ & $35(87.50 \%)$ & $0(0.0 \%)$ & $0(0.0 \%)$ \\
Anti-MCV $(>20 \mathrm{IU} / \mathrm{ml})$ & $16(80.0 \%)$ & $18(90.0 \%)$ & $34(85.00 \%)$ & $2(10.0 \%)$ & $2(10.0 \%)$ \\
\hline
\end{tabular}

Data are expressed as number (\%); anti- $\mathbf{M C V}$ anti-mutated citrullinated vimentin antibodies;

$\boldsymbol{R} \boldsymbol{F}$-IgM rheumatoid factor IgM; anti-CCP anti-cyclic citrullinated peptide.

Table 3. Comparison of the serum levels of RF-IgM, anti-CCP, Anti-MCV, and DAS28 among patients with early rheumatoid arthritis (RA) and RA patients with late disease.

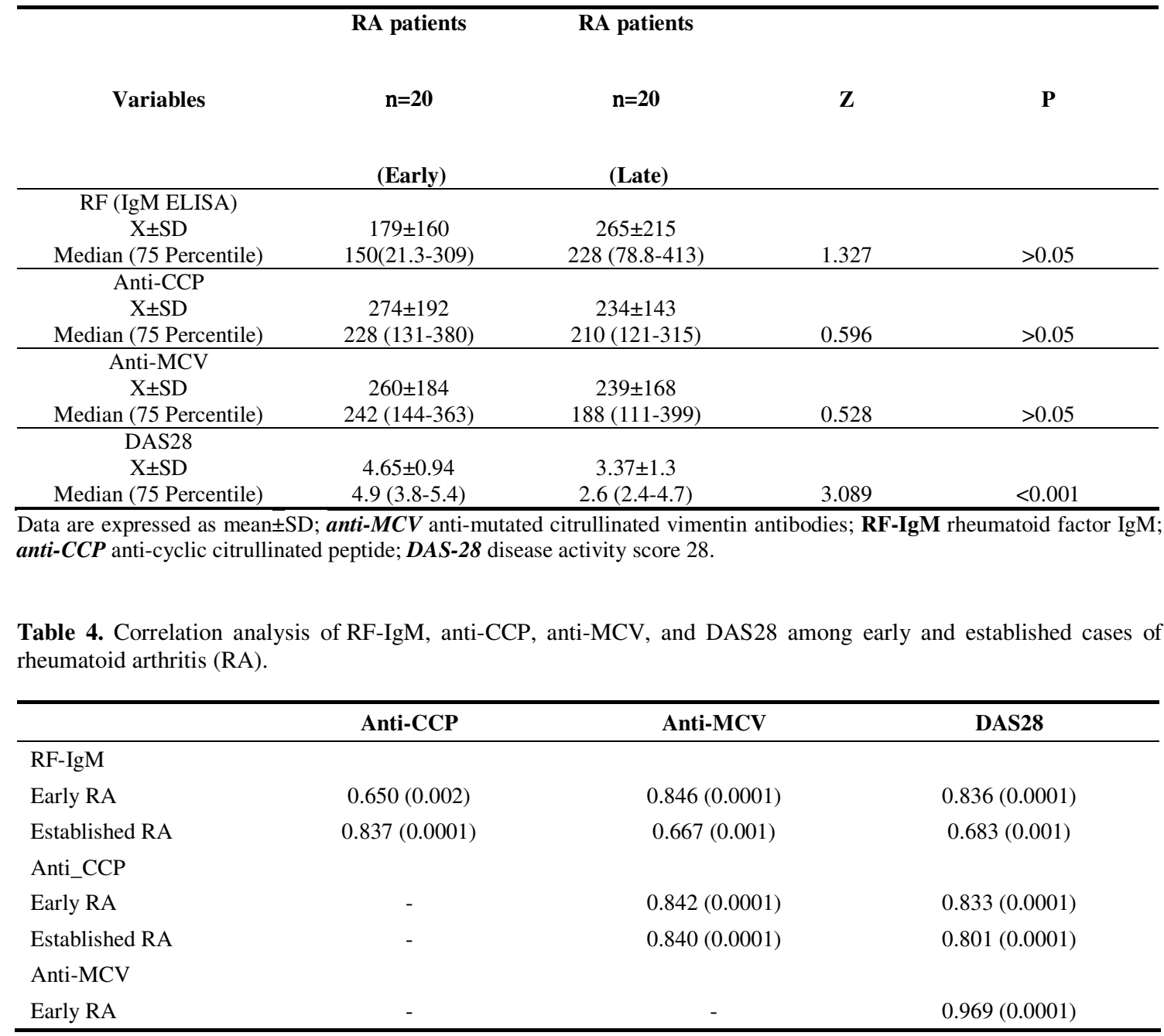


Established RA

$0.714(0.0001)$

Anti-MCV anti-mutated citrullinated vimentin antibodies; $\boldsymbol{R F}$-IgM rheumatoid factor IgM;

Anti-CCP anti-cyclic citrullinated peptide; $\boldsymbol{D A S 2 8}$ disease activity score 28.

Table 5. Distribution of the rheumatoid arthritis patients according to the presence of anti-MCV, anti-CCP, and IgM-RF.

\begin{tabular}{lcc}
\hline \multicolumn{1}{c}{ Variables } & RF-IgM +ve & RF-IgM -ve \\
& $(\mathbf{n = 2 9 )}$ & $(\mathbf{n}=\mathbf{1 1})$ \\
& & \\
\hline Anti-MCV+(>20 IU/m l) & $25(86.20 \%)$ & $9(81.80 \%)$ \\
Anti-MCV- $(\leq 20 \mathrm{I} \mathrm{U} / \mathrm{ml})$ & $4(13.80 \%)$ & $2(18.20 \%)$ \\
Anti-CCP + $(>25 \mathrm{IU} / \mathrm{ml})$ & & $4(36.00 \%)$ \\
Anti-MCV+ & $26(89.50 \%)$ & $2(18.20 \%)$ \\
Anti-MCV- & $3(10.30 \%)$ & \\
Anti-CCP - $(<25 \mathrm{IU} / \mathrm{ml})$ & & $1(9.09 \%)$ \\
Anti-MCV+ & $2(6.80 \%)$ & $1(9.09 \%)$ \\
Anti-MCV- & $1(3.40 \%)$ & \\
\hline
\end{tabular}

Data are expressed as number (\%); $\boldsymbol{A n t i - M C V}$ anti-mutated citrullinated vimentin antibodies;

$\boldsymbol{R F}$-IgM rheumatoid factor IgM; $\boldsymbol{A n t i - C C P}$ anti-cyclic citrullinated peptide.

Table 6. Sensitivity and specificity of anti-MCV antibodies, anti-CCP antibodies, and RF-IgM in rheumatoid arthritis (RA) patients.

\begin{tabular}{ccccccc}
\hline Parameter & Cutoff & Sensitivity & Specificity & PPV & NPV & Eff. \\
\hline RF-IgM & 44 & 72.5 & 97.1 & 96.7 & 75.6 & 84.0 \\
Anti-CCP & 20 & 95.0 & 100 & 100 & 94.6 & 97.3 \\
Anti-CMV & 22.7 & 95.0 & 97.1 & 97.4 & 94.4 & 96.0 \\
\hline
\end{tabular}

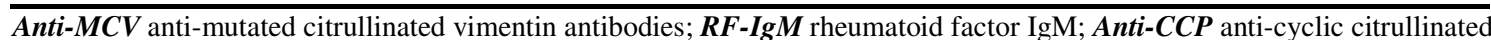
peptide; $\boldsymbol{P P V}$ Positive predictive value; $\boldsymbol{N P V}$ Negative predictive value; $\boldsymbol{E} f \boldsymbol{f}$. Efficacy

\section{DISCUSSION}

Since the switch in paradigm in treatment of RA from retarding the start of therapy to early aggressive therapy-and since the introduction of biologic drugs, the development of the disease can now be effectively delayed or sometimes even be halted. So, it is particularly important to identify new diagnostic markers which might permit diagnosis of RA as soon as possible. ${ }^{16,17}$

Although the precise etiology of RA remains unknown, there is strong evidence for autoimmunity since several auto-antibodies are associated with the disease. Besides the rheumatoid factor (RF), the anticitrullinated peptide antibodies (ACPA) have recently been included in the new diagnostic criteria for RA that has been developed by the EULAR/ACR panel. ${ }^{13}$
In the present study, (60) Egyptian patients with different rheumatic diseases, were enrolled in a cross section study. All were tested by the newly developed ELISA for the presence of anti-MCV: Out of 40 RA patients, $34(85 \%)$ tested positive for anti-MCV (mean \pm SD, 249 \pm 174 ), as did as did 1/8 SLE patients $(12.5 \%), 1 / 7$ Psoriatic arthritis patients $(14.3 \%)$ and none of the SpA patients tested positive for the antiMCV antibodies. Anti-MCV sensitivity and specificity were $95.0 \%$ and $97.1 \%$, respectively, with positive predictive value of 97.4 at cut-off value $22.7 \mathrm{U} / \mathrm{L}$. In partial agreement with these results Al-Shukaili et al. (2012), who studied anti-MCV antibodies in 80 patients with RA and 133 healthy volunteers and reported that Anti-MCV sensitivity and specificity were $72.0 \%$ and $87 \%$, respectively, with positive predictive value of 0.93 at cut-off value $20 \mathrm{U} / \mathrm{L}$. These differences can be attributed to genetic differences. 
However; they totally agree with our results that recorded the anti-CCP antibodies to have higher diagnostic specificity and positive predictive value than RF and anti-MCV antibodies. ${ }^{18}$

Other studies estimated the sensitivity and specificity of the anti-citrullinated peptide antibodies (ACPA) (anti-CCP antibodies, and anti-MCV antibodies) in RA, other autoimmune diseases and in healthy controls reported heterogeneous results. In study made by Nicaise Roland et al. (2008), they reported that the specificity of anti-MCV antibody was lower than that of anti-CCP, $(90.9 \% \& 94.7 \%)^{7}$ In the study of Hannah et al. (2007) reported the same finding but with lower values $(87 \% \text { \& } 90 \%)^{2}$. However; Liu et al. (2009) showed that the sensitivity of anti-MCV antibodies, was higher than that of antiCCP antibodies and RF $(78.2 \%, 61.8 \%$, and $72.4 \%$, respectively $)^{19}$, while our results revealed that both anti-CCP antibodies, and anti-MCV antibodies have equal sensitivity (95\%).

On further comparison of our results with that of Nicaise Roland et al., it was found that $6.8 \%$ of antiCCP negative RA patients were positive for anti-MCV (vs11.8\% in their study), 9\% of the patients having negative tests for anti-CCP, and RF were anti-MCV antibodies positive (vs7.9\% in their study), and3.4\% of anti-CCP negative patients who also tested negative for anti-MCV had positive RF titres (vs13.2\% in their study). ${ }^{7}$ Therefore, it may be better to assay both anti$\mathrm{MCV}$ and anti-CCP in RF -negative RA patients without replacing them.

The present study revealed that the serum levels of RF, Anti-CCP, and Anti-MCV were significantly higher in RA patients than the disease and healthy controls groups, and their levels were highly significantly correlated with the disease activity score (DAS 28) of the RA patients this results occurred in accordance with G. Keskin et al., 2008 who reported that The mean serum anti-MCV levels were correlated with DAS $28(r=0.531, p=0.001)$, VAS score $(r=0.332$, $\mathrm{p}=0.01)$, ESR $(\mathrm{r}=0.458, \mathrm{p}=0.001)$, serum CRP levels $(\mathrm{r}=0.568, \mathrm{p}=0.01)$, serum $\mathrm{RF}$ levels $(\mathrm{r}=0.529$, $\mathrm{p}=0.001)$, swollen joints number $(\mathrm{r}=0.525, \mathrm{p}=0.001)$ and tender joints number $(\mathrm{r}=0.638, \mathrm{p}=0.001){ }^{20}$

On the other hand there were no significant differences in the mean serum levels of RF, Anti-CCP, and Anti-MCV between the early and established cases of RA. This finding disagree with the results of Al-Shukaili et al. (2012), who found that both anti$\mathrm{CCP}$ and anti-MCV antibodies are present in very early stages of $\mathrm{RA}^{18}$. While, Mathsson et al. (2008) reported that in early RA patients anti-MCV yields greater sensitivity and unchanged specificity when compared with the anti-CCP antibodies. ${ }^{21}$

In conclusion, the results of this study for antiMCV antibodies were comparable with other reported results with different ethnic groups, and it could suggested that anti-MCV and anti-CCP are complementary to enhance sensitivity of RA diagnosis as anti-MCV antibodies were found in some cases of RA patients without anti-CCP and that an equivalent number of anti-CCP-positive RA patients tested negative for anti-MCV.

Long term (5-7 years) monitoring of a large numbers of healthy controls of different ethnic groups with high titer of anti-MCV antibodies is recommended to assess the predictive value of antiMCV antibodies.

[Disclosure: Authors report no conflict of interest]

\section{REFERENCES}

1. J. Avouac, L. Gossec, M. Doodads: Diagnostic and predictive value of anti-cyclic citrullinated protein antibodies in rheumatoid arthritis: a systematic literature review. Annals of the Rheumatic Diseases 2006, 65(7): 845-851.

2. Poulsom H, Charles PJ: Antibodies to citrullinated vimentin are a specific and sensitive marker for the diagnosis of rheumatoid arthritis. Clin Rev Allergy Immunol 2008, 34: 4-10.

3. ŞAHIN Ö, KAPTANOĞLU E, BAKICI MZ: Diagnostic Value of Autoantibodies Against Citrullinated Peptide Antigens in Rheumatoid Arthritis: Comparison of Different Commercial Kits. Turk J Rheumatol 2011, 26(1):13-18.

4. Shmerling RH, Delbanco TL: How useful is the rheumatoid factor? An analysis of sensitivity, specificity and predictive value. Arch Intern Med. 1992, 152: 2417-2420.

5. Klareskog L, Rönnelid J, Lundberg K, Padyukov L, Alfredsson L: Immunity to citrullinated proteins in rheumatoid arthritis. Annu Rev Immunol 2008, 26: 651-675.

6. Engelmann R, Brandt J, Eggert M, Karberg K, et al.: IgG1 and IgG4 are the predominant subclasses among auto-antibodies against two citrullinated antigens in RA. Rheumatology (Oxford) 2008, 47: 1489-1492.

7. Nicaise PR, Grootenboer SM, Bruns A, Hurtado $\mathrm{M}$, et al.: Antibodies to mutated citrullinatedvimentin for diagnosing rheumatoid arthritis in anti-CCP-negative patients and for monitoring infliximab therapy. Arthritis Res Ther. 2008, 10(6): R142.

8. Van der Linden MP, van der Woude D, IoanFacsinay A, Levarht EW, et al.: Value of antimodified citrullinatedvimentin and third-generation anti-cyclic citrullinated peptide compared with second-generation anti-cyclic citrullinated peptide and rheumatoid factor in predicting disease outcome in undifferentiated arthritis and 
rheumatoid arthritis. Arthritis \& Rheumatism 2009, 60: 2232-2241

9. Vossenaar ER, Radstake TR, van der Heijden A, van Mansum MA, et al.: Expression and activity of citrullinating peptidyl arginine deiminase enzymes in monocytes and macrophages. Ann Rheum Dis. 2004, 63: 373-381.

10. Hayem G, Chazerain P, Combe B, Elias A, et al.: Anti-Sa antibody is an accurate diagnostic and prognostic marker in adult rheumatoid arthritis. J Rheumatol. 1999, 26: 7-13.

11. Soos L, Szekanecz Z, Szabo Z, Fekete A, et al.: Clinical evaluation of anti-mutated citrullinated vimentin by ELISA in rheumatoid arthritis. J Rheumatol. 2007, 34: 1658-1663.

12. Arnett FC, Edworthy SM, Bloch DA: The American Rheumatism Association 1987, revised criteria for the classification of rheumatoid arthritis. Arthritis Rheum. 1987, 31: 315-24.

13. Mitchel L. Zoler: New Rheumatoid Arthritis Criteria Released by ACR/EULAR Panel [Monday, October 26, 2009-Elsevier Global Medical News].

14. Prevoo ML: Modified disease activity scores that include 28 joint counts. Arthritis Rheum. 1995, 38: 4448.

15. Bedell SE, Bush BT: Erythrocyte sedimentation rate. From folklore to facts. Am J Med 1985, 78: 10011009 .
16. Gross WL, Moosig F, Lamprecht P: Anti citrullinated protein/peptide antibodies in rheumatoid arthritis. Dtsch Arztebl Int. 2009, 106(10): 157-158.

17. Niewold TB, Harrison MJ, Paget SA: Anti-CCP antibody testing as a diagnostic and prognostic tool in rheumatoid arthritis. QJM 2007, 100(4): 193-201.

18. Al-Shukaili A, Al-Ghafri S, Al-Marhoobi S, Alkaabi J: Evaluation of Anti-Mutated Citrullinated Vimentin Antibodies, Anti-Cyclic Citrullinated Peptide Antibodies and Rheumatoid Factor in Omani Patients with Rheumatoid Arthritis. International Journal of Rheumatology, vol. 2012, Article ID 285854, 5 pages.

19. Liu X, Jia R, Zhao J, Li Z: The role of anti-mutated citrullinated vimentin antibodies in the diagnosis of early rheumatoid arthritis. Journal of Rheumatology 2009, 36(6): 1136-1142.

20. Keskin G, Inal A, Keskin D: Diagnostic utility of anti-cyclic citrullinated peptide and anti-modified citrullinated vimentin antibodies in rheumatoid arthritis. Protein and Peptide Letters 2008, 15(3): 314-317.

21. Mathsson L, Mullazehi M, Wick MC: Antibodies against citrullinated vimentin in rheumatoid arthritis: higher sensitivity and extended prognostic value concerning future radiographic progression as compared with antibodies against cyclic citrullinated peptides. Arthritis\& Rheumatism 2008, 58(1): 36-45 